\title{
Characterization of pathogenic or non-pathogenic Enterococcus faecalis isolated from lambs from Xinjiang, a remove North-west province of China
}

\author{
ZHOU Xia*, WANG Dong and WANG Xiao-lan \\ College of Animal Science and Technology, Xinjiang Shihezi University, Shihezi, 832003, China.
}

Accepted 23 August, 2011

\begin{abstract}
The majority of the 11 pathogenic Enterococcus faecalis from lambs developed encephalitis and 45 non-pathogenic $E$. faecalis from intestinal and respiratory microbiota of healthy lambs were belonged to Streptococcus serotype D. Haemolytic study revealed that 8 of 11 pathogenic stains had stable haemolyticus; $8 / 30$ strains of intestinal normal microbita and 3 of 15 strains from respiratory system showed unstable haemolyticus. Of 11 pathogenics $E$. faecalis, 8 of 9 virulence factor genes were detected in all the strains; 5 of 11 expressed Esp, CylA, Asa1, Ace, efa, EF0591 and EF3314 simultaneously and 1 of 11 expressed GelE; Two of 11 did not express any of the 9 virulence factor genes. Among 30 strains isolated from the intestinal microbita, only one had 2 (GelE, EF3314) and one had 3 (GelE, EF3314 and Asa1) of the 9 virulence factor genes. The homology of these 3 common virulence gene fragments (GelE, EF3314 and Asa1) was more than 95\% between $E$. faecalis from GenBank and intestinal microbita and $96 \%$ when comparing the $E$. faecalis isolated from intestinal microbita and from those of pathogenic strains. Antibiotic sensitivity study indicated that all of the 11 pathogenic strains were resistance to a variety of antibiotics in various degrees. In comparison, Only 2 strains from normal flora were resistance to individual antibiotics. In vivo challenge study showed that all of the 11 the pathogenic strains could lead to the death of mice, whereas none of the isolates from normal flora could cause the death of the experimental animals.
\end{abstract}

Key words: Biochemical characteristic, Enterococcus faecalis, lamb,virulence factor gene.

\section{INTRODUCTION}

Enterococcus faecalis are an important part of normal flora in humans and animals. It is the second regular bacteria, following to $E$. coli as ecological agents (Yuan and Fu, 2003; Drahovska et al., 2004). Recent studies have confirmed that the pathogenicity of $E$. faecalis is an important nosocomial infectious pathogen after Staphylococcus in the aerobic Gram-positive cocci (Schaberg et al., 1991). E. faecalis today is ranked second to third in frequency among bacteria isolated from hospitalized patients (Kayse, 2003). Treatment for $E$.

\footnotetext{
*Corresponding author. E-mail: zhouxia0993@yahoo.com.cn. Tel: +86 993-2058721; +86 13031326366. Fax: +86 9932038582.
}

faecalis is difficult due to the possession of a large number of virulence factors and drug resistant. So the study on $E$. faecalis has become one hot point in medical research (Giridhara Upadhyaya et al., 2009; Katie Fisher, 2009). There are also reports of infection in livestock and poultry in the veterinary practice, but the relationship between pathogenic and normal flora $E$. faecalis and its pathogenic mechanisms are not yet very clear.

We have 11 isolated $E$. faecalis from Lamb encephalitis recently, but the relationship between pathogenic strain and normal flora isolates from healthy lamb is unclear.

So our purpose is to make a comparative study on different sources of $E$. faecalis from lamb, such as culture characteristics, biochemical features, hemolytic characterristics, drug susceptibility, animal corresponding pathogenicity and the types of virulence factor genes and 
the fragments nucleotide sequence, which can provide information for pathogenic mechanism of animal $E$. faecalis infection.

\section{MATERIALS AND METHODS}

\section{Reagents}

TaqDNA polymerase and DNA gradient ladders were obtained from Shanghai Sangon Bio-Engineering Company. Streptococcus Grouping Kit was obtained from the France BioMerieux Inc. Fetal bovine serum was obtained from Hangzhou Sijiqing Biological Engeering Material Co., Ltd. China. Antibiotics were purchased from Hangzhou Tianhe Microorganism Regent Co., Ltd China.

\section{Isolation of $E$. faecalis}

Eleven pathogenic $E$. faecalis were isolated from lamb brains which had developed encephalitis and were identified. Thirty and fifteen $E$. faecalis of normal flora were isolated from intestinal microbiota and respiratory microbiota of healthy lambs, respectively.

\section{Growth characteristics of isolates}

The purified $E$. faecalis were inoculated on ordinary nutrient agar plate, Streptococcus selective blood agar medium, LB blood agar medium, and incubated at $37^{\circ} \mathrm{C}$ under $10 \% \mathrm{CO}_{2}$ for $24 \mathrm{~h}$.

\section{Culture characteristics of the isolates}

A single bacteria colony was picked up from blood agar plate after $24 \mathrm{~h}$ and was inoculated in LB broth with $5 \%$ fetal bovine serum with or without $10 \% \mathrm{CO}_{2}$ in order to test the requirement for oxygen. To test the tolerance to temperature, the isolates were inoculated in LB broth with $5 \%$ fetal bovine serum at either $40^{\circ} \mathrm{C}$ or $10^{\circ} \mathrm{C}$ for $24 \sim$ $48 \mathrm{~h}$. To test the tolerance to high-salt or high-alkali, the isolates were inoculated in LB broth containing $5 \%$ fetal bovine serum with either $6.5 \% \mathrm{NaCl}$ or $\mathrm{pH} 9.6$ at $37^{\circ} \mathrm{C}$ for $24 \sim 48 \mathrm{~h}$.

\section{Biochemical characterization of the isolates}

Isolates from blood agar after $24 \mathrm{~h}$ were identified by VITEKAMS32 Bacterial Biochemical Identification System. Hemolysis to sheep red blood cells were determined by plate assay (PA) ( $\mathrm{Li}$ and $\mathrm{Li}$, 1999). Serotype of the isolates was identified by use of Streptococcus Grouping Kit.

\section{Antimicrobial susceptibility test (disk diffusion method)}

15 to $20 \mathrm{~mm}$ zone of inhibition is high-sensitive, 10 to $14 \mathrm{~mm}$ is the medium-sensitive, $10 \mathrm{~mm}$ below is low- sensitive, $0 \mathrm{~mm}$ is nonsensitive according the standards adopted from United States Committee for Standardization of Clinical Trials. Antibacterial drugs include gentamicin, tetracycline, norfloxacin, streptomycin 2000, penicillin vancomycin, nitrofurantoin, chloramphenicol, rifampicin and erythromycin.

\section{Mice and infection}

Group of 3 Kunming out-bred mice, 6 to 8 weeks old, female, were obtained from Xinjiang Medical University, China. For infection study, all of the 11 pathogenic strains, 10 randomly picked strains of intestinal isolates and 10 stains of respiratory isolates were injected and was infected with intra-peritoneally (i.p.) with $3 \times 10^{8}$ bacteria per mouse in Martin broth. Control group was injected with LB broth alone.

Detection of 9 types of virulence factor genes and sequence analysis

Virulence factor genes include haemolysin activator (Cyl A), gelatinase (GelE), enterococcal surface proteins (Esp), endocarditis antigen (EfaA), collagen-binding protein(Ace), aggregation substances(Asa373 and Asa1), another 2 protein EF0591 and EF3314. The PCR primers synthesized according to reference (Roberta et al, 2004) were showed in Table 1. and normal flora strains reference Molecular Cloning (Sambrook and Russell, 2002) with a slight modification. The homologous of DNA fragments were analyzed with ClustalX sequence analysis software.

\section{RESULTS}

\section{Growth and cultivation characteristics of isolates}

Most of the $E$. faecalis isolated from the three different sources were long-chain and Gram-positive coccus in 2 kind of liquid cultures (Figure 1). In aging cultures they sometimes became Gram-negative. Colonies were round, smooth, moist, medium-sized with neat edge in blood agar LB plate after anaerobic culture. They also produced the colonies which are colorless, transparent, round, surface wet, slightly smooth, neat edge, like tip in Streptococcus select agar medium. Those isolates almost can not grow or grow poorly in the ordinary medium and make Streptococcus enrichment medium become slightly turbid and a small amount of flocculent precipitate at the bottom of tube. All strains can grow at $45^{\circ} \mathrm{C}$ and $10^{\circ} \mathrm{C}$ and also grow in $6.5 \% \mathrm{NaCl}$ or $\mathrm{pH} 9.6 \mathrm{LB}$ broth with serum. These features are consistent with characteristics of $E$. faecalis.

\section{Biochemical characteristics of isolates}

Biochemical reactions of 45 strains from normal flora were the same as that of 11 pathogenic strains when assayed with VITEK-AMS 32 systems. Butyl-diphenylpyrazole dione (PYR) test is positive; Cyclic Adenosine monophosphate test, Optochin test and bacitracin inhibition test are negative; These isolates can ferment glucose and produce L-lactic acid mainly; Catalase test is negative, but some strains can produce false catalase; Benzidine test is negative. Eight of 11 pathogens produce $\beta$-hemolysis in sheep blood agar, which is relatively stable after continuous passage. Eight of 30 strains from intestinal microbiota and 3 of 15 strains from respiratory microbiota also produce hemolysis, but these characteristics disappear after continuous passage. The results of serotypes showed that 8 of 11 were type D, 1 of 
Table 1. Information of PCR primers for detection of different virulence factor genes.

\begin{tabular}{|c|c|c|c|c|}
\hline $\begin{array}{l}\text { Name of } \\
\text { virulence vector genes }\end{array}$ & Sequence of primer & $\begin{array}{c}\text { Length of } \\
\text { Segment (bp) }\end{array}$ & $\begin{array}{l}\text { GenBank } \\
\text { accession No. }\end{array}$ & Location \\
\hline \multirow{2}{*}{ Esp } & TTG CTA ATG CTA GTC CAC GAC C & \multirow[t]{2}{*}{932} & \multirow[t]{2}{*}{ AF034779 } & \multirow[t]{2}{*}{$1217-1249$} \\
\hline & GCC TCA ACA CTT GCA TTG CCG A & & & \\
\hline \multirow{2}{*}{ GelE } & ACC CCG TAT CAT TGG TTT & \multirow[t]{2}{*}{405} & \multirow[t]{2}{*}{ M37185 } & \multirow[t]{2}{*}{$762-1163$} \\
\hline & CAG CAT TGC TTT TCC ATC & & & \\
\hline \multirow{2}{*}{ CylA } & GAC TCG GGG ATT GAT AGG C & \multirow[t]{2}{*}{688} & \multirow[t]{2}{*}{ AD1CLYL } & \multirow[t]{2}{*}{$6656-734$} \\
\hline & GCT GCT AAA GCT GCC CTT AC & & & \\
\hline \multirow{2}{*}{ Asa1 } & CCA GCC AAC TAT GGC GGA ATC & \multirow[t]{2}{*}{529} & \multirow[t]{2}{*}{ SFPASA 1} & \multirow[t]{2}{*}{$3122-3651$} \\
\hline & CCT GTC GCA AGA TCG ACT GTA & & & \\
\hline \multirow{2}{*}{ Asa373 } & GGA CGC ACG TAC ACA AAG CTA C & \multirow[t]{2}{*}{619} & \multirow[t]{2}{*}{ AJ132039 } & \multirow[t]{2}{*}{$3094-3713$} \\
\hline & CTG GGT GTG ATT CCG CTG TTA & & & \\
\hline \multirow{2}{*}{ Ace } & GGA ATG ACC GAG AAC GAT GGC & \multirow[t]{2}{*}{616} & \multirow[t]{2}{*}{ AF159247 } & \multirow[t]{2}{*}{$160-776$} \\
\hline & GCT TGA TGT TGG CCT GCT TCC G & & & \\
\hline \multirow{2}{*}{ EfaA } & GCC AAT TGG GAC AGA CCC TC & \multirow[t]{2}{*}{688} & \multirow[t]{2}{*}{ EFU03756 } & \multirow[t]{2}{*}{$312-1000$} \\
\hline & CGC CTT CTG TTC CTT CTT TGG C & & & \\
\hline \multirow{2}{*}{ EF0591 } & AGA GGG ACG ATC AGA TGA AAA A & \multirow[t]{2}{*}{844} & \multirow[t]{2}{*}{ NC_004668 } & \multirow[t]{2}{*}{$99-1003$} \\
\hline & ATT CCA ATT GAC GAT TCA CTT C & & & \\
\hline \multirow{2}{*}{ EF3314 } & AGA GGG ACG ATC AGA TGA AAA A & \multirow[t]{2}{*}{566} & \multirow[t]{2}{*}{ NC_004668 } & \multirow[t]{2}{*}{$35-601$} \\
\hline & ATT CCA ATT GAC GAT TCA CTT C & & & \\
\hline
\end{tabular}

Note: Primer references (Roberta et al., 2004).

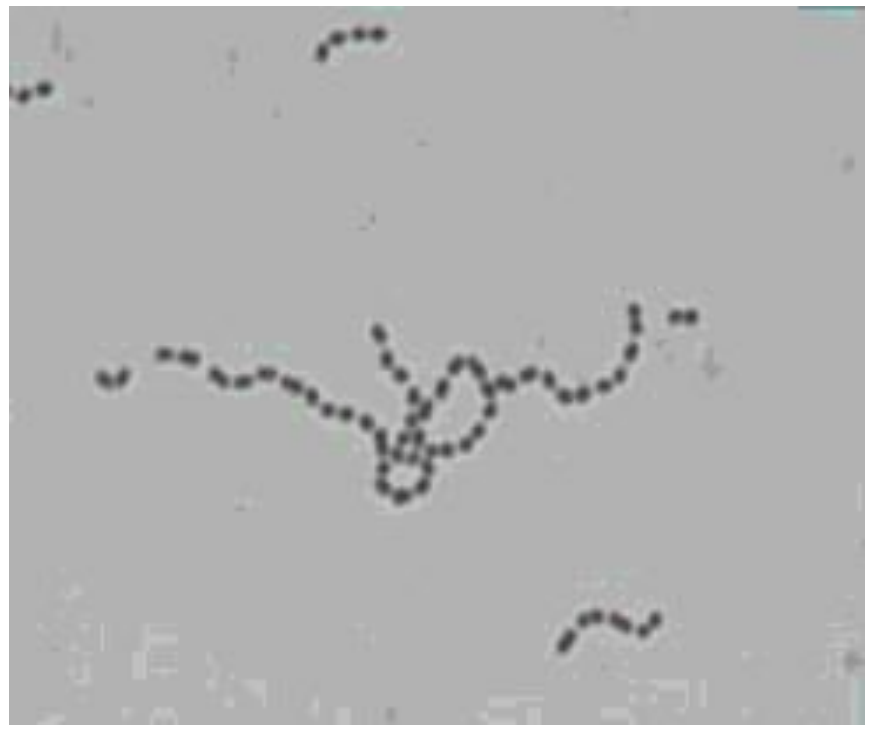

Figure 1. Gram staining of the pathogenic E. faecalis $s$ cultivated in broth $(100 x)$ The E. faecalis were isolated from brains of infected lamb. They were cultured in broth for $18 \mathrm{~h}$. The bacteria were stained long-chain and Gram-positive coccus.

11 is type G, 2 of 11 is not identified in pathogens; Twenty-four of 30 are type D, 6 of 30 are not identified from intestinal microbiota; Fifteen of 15 are type $D$ from respiratory microbita.

\section{Antibiotic susceptibility test}

Eleven pathogenic isolates were highly sensitive to nitrofurantoin and moderately sensitive to chloramphenicol, 
Table 2. Antibiotics susceptibility test of the E. faecalis isolated from the three sources.

\begin{tabular}{|c|c|c|c|c|c|c|c|c|c|c|c|}
\hline \multicolumn{2}{|c|}{ Antibiotic category } & 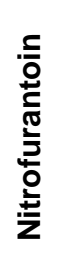 & 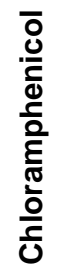 & 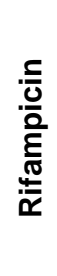 & 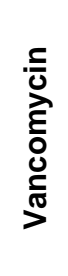 & 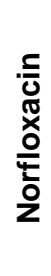 & $\frac{. \subseteq}{\overline{\bar{D}}}$ & 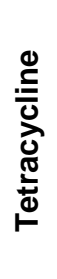 & 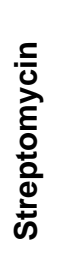 & 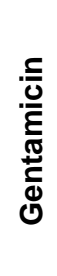 & 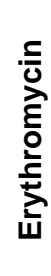 \\
\hline \multirow{8}{*}{$\begin{array}{l}\text { E. faecalis } \\
\text { strains from } \\
\text { lambs }\end{array}$} & \multicolumn{11}{|c|}{ Pathogenic strains } \\
\hline & $1-11$ & $\mathrm{~S}$ & $S$ & $S$ & $S$ & $\mathrm{R}$ & $\mathrm{R}$ & $\mathrm{R}$ & $\mathrm{R}$ & $\mathrm{R}$ & $\mathrm{R}$ \\
\hline & \multicolumn{11}{|c|}{ Intestinal strains } \\
\hline & $1-29$ & $\mathrm{~S}$ & $\mathrm{~S}$ & $\mathrm{~S}$ & $\mathrm{~S}$ & $\mathrm{~S}$ & $\mathrm{~S}$ & $\mathrm{~S}$ & $\mathrm{~S}$ & $\mathrm{~S}$ & $\mathrm{~S}$ \\
\hline & 30 & $\mathrm{~S}$ & $\mathrm{~S}$ & $\mathrm{~S}$ & $\mathrm{~S}$ & S & $S$ & $\mathrm{R}$ & $\mathrm{R}$ & $S$ & $\mathrm{R}$ \\
\hline & \multicolumn{11}{|c|}{ Respiratory strains } \\
\hline & $1-14$ & $\mathrm{~S}$ & $\mathrm{~S}$ & $\mathrm{~S}$ & $\mathrm{~S}$ & S & $S$ & $\mathrm{~S}$ & $\mathrm{~S}$ & $\mathrm{~S}$ & $\mathrm{~S}$ \\
\hline & 15 & $\mathrm{~S}$ & $\mathrm{~S}$ & $\mathrm{~S}$ & $\mathrm{~S}$ & $\mathrm{~S}$ & $\mathrm{R}$ & $\mathrm{S}$ & $\mathrm{S}$ & $\mathrm{S}$ & $\mathrm{S}$ \\
\hline
\end{tabular}

Table 3. In vivo study of the pathogenicity of the stains isolated from different sources. Each of the E. faecalis strains isolated from 3 sources was infected into three mice (see Material and Methods). By $24 \mathrm{~h}$ post-infection, the numbers of the dead mice were recorded. No more death of the mice was observed after $24 \mathrm{~h}$.

\begin{tabular}{lllllllllllll}
\hline \multicolumn{11}{c}{ Numbers of mice died / numbers of mice infected } \\
\hline Infected with pathogenic strains & $2 / 3$ & $3 / 3$ & $3 / 3$ & $3 / 3$ & $3 / 3$ & $3 / 3$ & $3 / 3$ & $2 / 3$ & $1 / 3$ & $2 / 3$ & $1 / 3$ \\
Infected with intestinal strains & $0 / 3$ & $0 / 3$ & $0 / 3$ & $0 / 3$ & $0 / 3$ & $0 / 3$ & $0 / 3$ & $0 / 3$ & $0 / 3$ & $0 / 3$ & \\
Infected with respiratory strains & $0 / 3$ & $0 / 3$ & $0 / 3$ & $0 / 3$ & $0 / 3$ & $0 / 3$ & $0 / 3$ & $0 / 3$ & $0 / 3$ & $0 / 3$ & \\
\hline
\end{tabular}

rifampicin and vancomycin. These isolates were resistant to norfloxacin, penicillin, tetracycline, streptomycin, gentamicin and erythromycin to various degrees. The rest of strains from normal flora were sensitive to the other antibiotic except that 1 of 30 strains from intestinal microbiota was resistant to tetracycline, erythromycin and streptomycin, 1 of 15 strains from respiratory microbita is resistant to penicillin (Table 2).

\section{Experimental infection of mice}

All mice infected with pathogenic strains appeared apathetic and back hair handstand $16 \mathrm{~h}$ after infection. Of 33 mice infected with the 11 pathogenic strains ( 3 mice per strain), 25 of 33 the mice died within $24 \mathrm{~h}$ postinfection. The mice infected with normal flora strains appeared temporary apathetic and loss of appetite, but they gradually recovered after $12 \mathrm{~h}$. The control group looked normal during the experiment (Table 3 and Figure 2).

\section{Results of virulence factor genes}

Nine virulence factor genes were listed in Table 1. Our gene analysis showed that 8 of 9 virulence factors were tested in the 11 pathogenic E. faecalis. Among the 11 pathogenic E. faecalis, five took Esp, CylA, Asa1, Ace, efa, EF0591 and EF3314 virulence factors genes, one strain had GelE only. Two strains did not take any of the 9 virulence factor genes (Figure 3 and Table 4). Of the 30 $E$. faecalis isolated from intestinal microbiota, three out of the nine virulence factor genes were detected in all of them. One of the normal strains had virulence factor genes GeIE and EF3314 and one took virulence factor genes GelE, EF3314 and Asa1. Of the 15 isolated from respiratory microbita, none of the virulence factor genes were detected among them (Figure 4 and Table 4). The Homology of amplified fragments of three common virulence factor genes is $99.53,96.2$ and $99.12 \%$, respectively between normal flora and pathogenic $E$. faecalis. Similarly, the homology from normal flora $E$. faecalis is $98.03,95$ and $99.3 \%$ compared to the information of GenBank from medical the cultural and biochemical characteristics of $E$. faecalis from normal flora were basically the same as that of pathogens except that the individual biochemical characteristics of individual strains were instable. These results were basically consistent with biochemical characteristics of $E$. faecalis. Haemolyticus is an important virulence indicator of certain bacteria. Eight of 11 pathogenic stains showed signifi- 


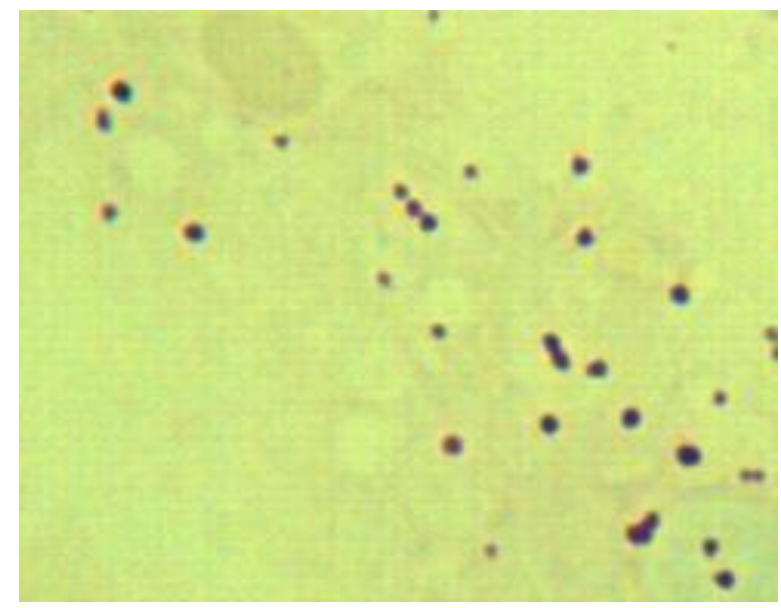

Figure 2. Wright's staining of the $E$. faecalis in encephalon of dead mice infected with pathogenic strains $(100 x)$. The brain smear of the infected mice was subject to Wright's staining. The $E$. faecalis were scattered or a very short strain including 2 to 3 bacteria in brain smear of mice infected with pathogenic strains.

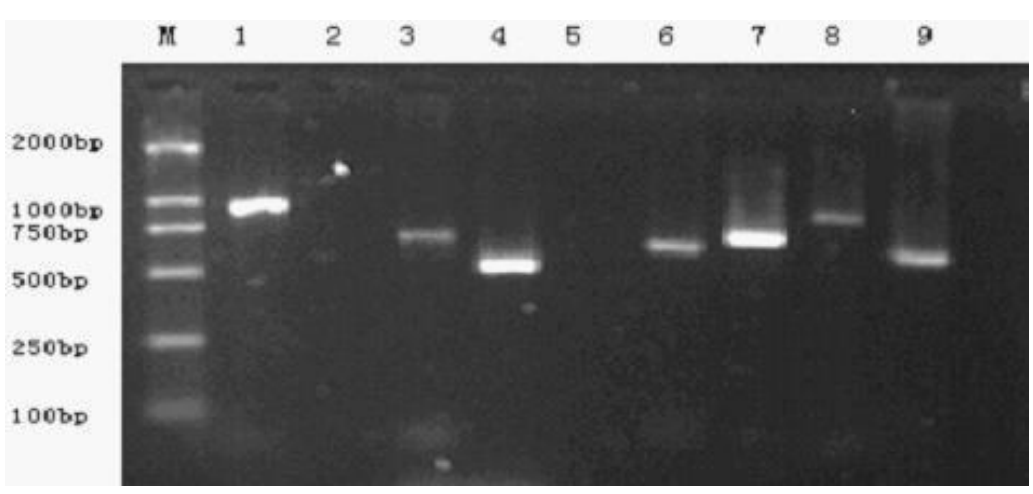

Figure 3. Virulence factor genes detected in stains No. 4 of pathogenic strains by PCR. M: Marker DL2000; 1: Esp; 2: GelE; 3: CylA; 4: Asa1; 5: Asa373; 6: Ace; 7: Efa; 8: EF0591; 9: EF3314. Nine virulence facter genes from the No. 4 pathogenic strains were amplified with PCR and the products were analysed by gel electrophoresis in $0.8 \%(\mathrm{w} / \mathrm{v})$ agarose gel.

Table 4. Detection of virulence factor genes by PCR. Nine virulence factor genes were tested in $E$. faecalis from 3 sources of lambs. Pathogenic strains have more combination of virulence factors gene than that of normal flora.

\begin{tabular}{|c|c|c|c|c|c|c|c|c|c|c|c|c|c|c|c|}
\hline \multirow{2}{*}{ Virulence factors gene } & \multicolumn{11}{|c|}{ Pathogenic strains } & \multicolumn{3}{|c|}{ Intestinal strains } & \multirow{2}{*}{$\begin{array}{c}\text { Respiratory strains } \\
1-15 \\
\end{array}$} \\
\hline & 1 & 2 & 3 & 4 & 5 & 6 & 7 & 8 & 9 & 10 & 11 & 1 & 2 & $3-30$ & \\
\hline Esp & + & + & + & + & - & + & + & + & - & + & - & - & - & - & - \\
\hline GelE & + & - & - & - & - & - & - & - & - & - & - & + & + & - & - \\
\hline CylA & - & + & + & + & + & + & + & - & - & + & - & - & - & - & - \\
\hline Asa1 & + & + & + & + & + & + & + & - & - & + & - & - & + & - & - \\
\hline Asa373 & - & - & - & - & - & - & - & - & - & - & - & - & - & - & - \\
\hline Ace & + & + & + & + & + & + & + & - & - & + & - & - & - & - & - \\
\hline efa & + & + & + & + & + & + & + & - & - & - & - & - & - & - & - \\
\hline EF0591 & - & + & + & + & + & + & + & - & - & + & - & - & - & - & - \\
\hline EF3314 & + & + & + & + & + & + & + & - & - & + & - & + & + & - & - \\
\hline
\end{tabular}

Note: + mean there is the virulence factor gene; - mean there is no the virulence factor gene. 


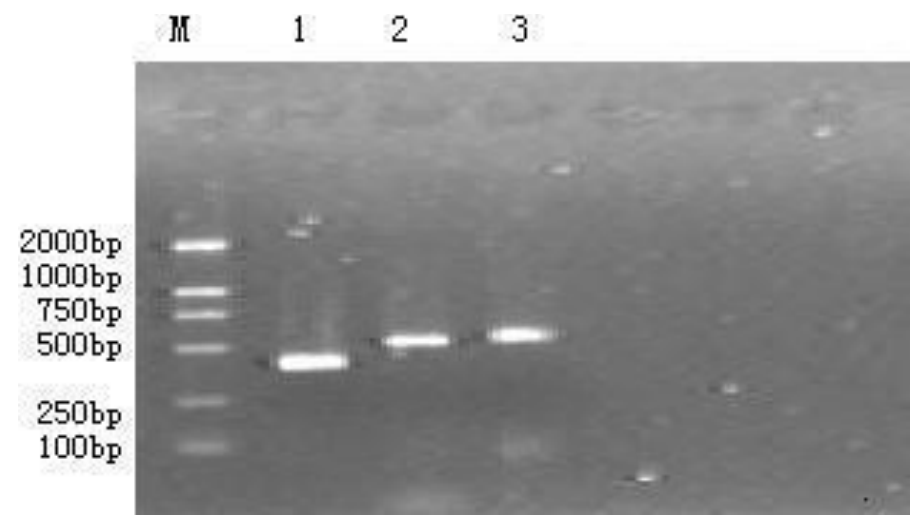

Figure 4. Virulence factor genes GelE, Asa1, and EF3314 were detected in stain No. 2 of the non-pathogenic stains isolated from the intestine by PCR. M: DL2000; 1: GelE; 2: Asa1; 3: EF3314. Nine virulence facter genes from the No. 2 non-pathogenic stains were amplified with PCR and the products were analysed by gel electrophoresis in $0.8 \%(\mathrm{w} / \mathrm{v})$ agarose gel.

Table 5. The homology (\%) of the 3 common virulence factor gene fragments from normal flora are compared among pathogenic $E$. faecalis and Genbank.PCR products of 3 common virulence factor gene fragments (GelE, Asa1 and EF3314 )cloned into vector, and sent them to Sangon Bio-Engineering Company for sequencing, then the homologous of DNA fragments were analyzed with ClustalX sequence analysis software.

\begin{tabular}{lccc}
\hline & E. faecalis from normal & Flora & \\
\hline & GelE & Asa1 & EF3314 \\
\cline { 2 - 4 } E. faecalis from GenBank & 98.03 & 95.00 & 99.30 \\
Pathogenic E. faecalis & 99.53 & 96.20 & 99.12 \\
\hline
\end{tabular}

cant hemolysis, and this feature did not disappear upon passages. While only 8 of 30 strains of normal flora showed hemolytic clinical isolates (GelE (M37185, Asa1 (X17214), and EF3314 (NC004668) (Table 5).

\section{DISCUSSION}

The results of biochemical characteristics showed that properties and it's hemolytic disappeared after the limited passages. Experimental infection of mice also verified this. All these evidences indicated that hemolytic of $E$. faecalis still was an indispensable factor in lambs encephalitis caused by $E$. faecalis.

The mechanism of drug resistant in $E$. faecalis is more complex, which include natural resistance, acquired drug resistance and multi-drug resistance (Zhang et al., 2001; $\mathrm{Li}$ and Zhang, 2004). Susceptibility test results indicated that the pathogenic strains were resistant to most antibiotics in various degrees,and individual strains from normal flora is also resistance to certain antibiotics, the reason for these phenomena in E. faecalis may be due to the complete manifestation of natural resistance and acquired drug resistance under the pressure of a large number of antibiotics used in clinic. Pathogenic strains were resistant to streptomycin, gentamicin and erythromycin. Interestingly, there were also individual strains of normal flora $E$. faecalis which were resistant to tetracycline, erythromycin and streptomycin, suggesting that drug resistance of $E$. faecalis was very universal. Researchers had confirmed that some drug resistant plasmid could be transferred each other among different sources $E$. faecalis or between $E$. faecalis and other bacteria (Launay et al., 2006; Simjee et al., 2006; Jacobsen et al., 2007). Multi-drug resistance genes could also be horizontally transferred between humans and poultry (Lim et al., 2006). Antibiotics are used widespread in animal husbandry and agriculture, which may increase the transmitted opportunity of $E$. faecalis drug resistance, including the $E$. faecalis in normal flora of humans and animals, these situation may give some $E$. faecalis from normal flora more opportunity to become pathogenic strains. Therefore, one should be very cautious when come to use any antibiotics in human medicine and veterinary practice.

Pathogenicity island usually was found in E. faecalis, there were several virulence factor genes in those pathogenicity island, different virulence factor genes had different roles in the course of infectious disease (Heikens et al., 2007, 2008; Dupont et al., 2008). Some 
researchers found that $E$. faecalis from different sources had different combination of virulence factor genes in medical clinic (Mannua et al., 2003; Roberta et al., 2004). The pathogenicity of $E$. faecalis from clinical isolates was more virulent than from that animal manure and dairy products. Our study indicated that virulence factor genes could be detected both in $E$. faecalis causing lambs encephalitis and in normal flora $E$. faecalis. But pathogenic isolates had more combination of virulence factor genes than the isolates of normal flora. This was basically consistent with the results which Roberta reported (Roberta et al., 2004). Our study showed that EF3314 and GelE appear in normal flora E. faecalis simultaneously, Maria also reported that GelE can be easily detected in E. faecalis from dairy ( Lopes et al., 2006). All these suggested that GelE has a high frequency in the non-pathogenic $E$. faecalis. Sequencing results showed that sequence homology of these 3 virulence factor gene fragments in normal flora $E$. faecalis (GelE, Asa1 and EF3314) was over 95 and $96 \%$ compared with corresponding sequence from GenBank and from $E$. faecalis causing lamb encephalitis. These results showed that the 3 virulence factor gene fragments had high homology among $3 \mathrm{E}$. faecalis from different sources of lamb. It suggests to us once again that there is a close relationship among $E$. faecalis from veterinary clinic, medical clinic and animal normal flora. We still do not know clearly the detailed mechanisms how $E$. faecalis from normal flora becomes pathogenic strains.

It is well known that $E$. faecalis is commonly used as microbial agent that has played a positive role on prevention of intestinal infectious diseases and regulation of microbiota homeostasis balance in recent years (Garcia et al., 2004). But we should also realize that $E$. faecalis as an ecological agent may artificially increase the opportunity to delivery the drug resistance and transfer virulence factor gene in the process of using these ecological agent considering its particularity.

\section{ACKNOWLEDGMENTS}

The first author acknowledges the financial support received from Department of Human Resources and Social Security in China.

\section{REFERENCES}

Drahovska H, Slobodnikova L, Kocincova D (2004). Antibiotic resistance and virulence factors among clinical and food Enterococcus isolated in Slovakia. Folia Microbiol., 49: 763-768.

Dupont H, Vael C, Muller-Serieys C (2008). Prospective evaluation of virulence factors of Enterococcus isolated from patients with peritonitis: impact on outcome. Diagn Microbiol. Infect. Dis., 60: 247255.
Garcia GA, Perez Morales R, Diaz Cinco M (2004). Resistance of Enterococcus strains isolated from pigs to gastrointestinal tract and antagonistic effect against Escherichia coli K88. Rev Latinoam Microbiol., 46: 5-12.

Giridhara Upadhyaya PM, Ravikumar KL, Umapathy BL (2009). Review of virulence factors of Enterococcus : An emerging nosocomial pathogen. Indian J. Med. Microbiol., 70: 301-306.

Heikens E, Bonten MJ, Willems RJ (2007). Enterococcal surfAce protein Esp is important for biofilm formation of Enterococcus faecium E1162. J. Bacteriol., 189: 8233-8241.

Heikens E, van Schaik W, Leavis HL, Bonten MJ (2008). Identification of a novel genomic island specific to hospital-acquired clonal complex 17 Enterococcus faecium isolates. Appl. Environ. Microbiol., 74: 7094-7098.

Jacobsen L, Wilcks A, Hammer K (2007). Horizontal transfer of tet(M) and erm $(B)$ resistance plasmids from food strains of Lactobacillus plantarum to E.faecalis $\mathrm{JH} 2-2$ in the gastrointestinal tractof gnotobiotic rats. FEMS Microbiol. Ecol., 59:158-167.

Katie Fisher CP (2009). The ecology, epidemiology and virulence of Enterococcus. Microbiology, 155: 1749-1757.

Kayse FH (2003). Safety aspects of Enterococcus from the medical point of view. Int. J. Food Microbiol., 88: 255-263.

Launay A, Ballard SA, Johnson PD, Grayson ML, Lambert T (2006). Transfer of vancomycin resistance transposon Tn1549 from Clostridium symbiosum to Enterococcus spp. in the gut of gnotobiotic mice. Antimicrob. Agents Chemother., 50: 1054-1063.

Li JQ, Li LJ (1999). Experiment Practice Guidance of Veterinary Microbiology. China Agriculture Press, Beijing, pp. 165-170.

Li S, Zhang Z (2004). Progress in Enterococcus resistance. Chinese J. Lab. Med., 27: 10-15.

Lim SK, Tanimoto K, Tomita H, Ike Y (2006). Pheromone-responsive conjugative vancomycin resistance plasmids in $E$. faecalis isolates from humans and chicken feces. Appl. Environ. Microbiol., 72: 65446554.

Lopes Mde F, Simões AP, Tenreiro R, Marques JJ, Crespo MT (2006). Activity and expression of a virulence factor, gelatinase, in dairy Enterococcus. International. Int. J. Food Microbiol., 112: 208-215.

Mannu L, Paba A, Daga E, Comunian R, Zanetti S, Duprè I, Sechi LA (2003). Comparison of the incidence of virulence determinants andantibiotic resistance between Enterococcus faecium strains of dairy, animal and clinical origin. Int. J. Food Microbiol., 88: 291-295.

Sambrook J, Russell DW (2002). Molecular cloning, 3nd ed. Cold Spring Harbor Laboratory Press, Cold Spring Harbor, N.Y.

Schaberg DR, Culver DH, Gaynes RP ( 1991) Major trends in the microbial etiology of nosocomial infection. Am. J. Med., 91: 72-76.

Simjee S, Zhang Y, McDermott PF, Donabedian SM, Zervos MJ, Meng J (2006). Heterogeneity of vat(E)-carrying plasmids in Enterococcus faecium recovered from human and animal sources. Int. J. Antimicrob. Agents, 28: 200-206.

Yuan JL, Fu XL (2003). The Study on Agent of Enterococcus faecium. J. Chinese Microecol., 15: 20-22.

Zhang KX, Tang YC, Zhang TT (2001). Isolation and drug-resistant of Enterococcus. China Hosp. Infect. J., 11: 233-237. 